\title{
Sleep and Academic Performance among Female Students in Al-Maarefa Colleges, 2015-2016
}

\author{
Abrar Sayer Al-mutairi*,Shrouq Ahmad Rahhal, Meriam Sadiq Al-abdullah, Zainab Hussain \\ Al-ibrahim, Mada Bejad Al-mutairi, Rawan Adel Shafaay, Reem Ahmad Alanazi, Handi Adnan \\ Al-mshel, Hadeel Maher Moqbel, Norah Abdullah Al-habshan.
}

College Of Medicine, Al-Maarefa Colleges for Science \& Technology, Riyadh, Saudi Arabia

*Corresponding author Abrar Sayer Al-mutairi, Email: abrarsayer@gmail.com, Mobile number: +966558178877

\begin{abstract}
Background: College students experience a number of sleep problems, which may impact academic performance, health, and mood. A common sleep problem among college students is sleep deprivation and resulting in excessive daytime sleepiness (EDS).

Objective: To identify the relationship between sleep and academic performance of female students.

Methods: An observational cross-sectional study was done in Al-Maarefa colleges during the time of 2015 to 2016. Information on sleep period and quality was collected by a self-administered questionnaire distributed on a sample of 150 students.

Main findings: Almost $71 \%$ of the students felt tired many times a week and felt sleepy during the day. Moreover, $87 \%$ of the students felt sleepy in lectures long time within the week. $68 \%$ of the students had 3.1-4 GPA on the preparatory year, and only 35\% of the students had 6-8 hours of the sleep per day. A strong relation was found between sleep hours on exam days and last GPA ( $\mathrm{p}=$ 0.005). Another relation was found between sleep hours on weekdays and the last GPA ( $p=0.04)$.

Conclusion: the data collected showed a high prevalence of insufficient sleep hours generally, and on nights before the exam specifically and a strong relationship between exam day sleeping hours and the final GPA. The average GPA is still high compared to the preparatory year GPA, even when the number of sleeping hours declined compared to a preparatory year.
\end{abstract}

Keywords: Sleep, Academic Performance, Female, Students

Introduction

College students experience a number of sleep problems, which may impact academic performance, health, and mood ${ }^{(\mathbf{1})}$ .A common sleep problem among college students is sleep deprivation and resulting in excessive daytime sleepiness (EDS). Both biological and social factors contribute to deprivation. Many college students are older adolescents and are still dealing with adolescent physiology such as a biologically driven delayed sleep phase ${ }^{(2)}$. $59 \%$ of adults 18 to 29 years of age describe themselves as night-owls. Unable to fall asleep earlier in the evening, they cannot get enough sleep if they must get up early. In addition, sleep may be voluntarily sacrificed due to social factors or involuntarily curtailed because of living in a noisy residence hall or apartment ${ }^{(3)}$. A typical coping technique for dealing with sleep deprivation is to attempt to make up for lost sleep by increasing sleep on the weekends, a practice that actually worsens the problem ${ }^{(4)}$. Sleep is believed to have facilitating role in learning and memory process. Sleep deprivation experiments conducted on humans have shown that sleep deprivation causes impairment of performance, vigilance, attention, concentration and memory ${ }^{(5)}$.

Sleep is defined by the medical dictionary as a period of rest for the body and mind, during which volition and consciousness are in partial or complete abeyance and the bodily functions partially suspended ${ }^{(6)}$. The sleep cycle is divided into 5 stages starting from a light sleep and ending in the REM stage. For a person to have a good quality sleep they must sleep through the 5 stages without any interruptions. Other factors affecting sleep is the time of sleep and number of hours slept ${ }^{(7)}$. According to the National Institutes of Health, the average adult sleeps less than seven hours per night. In today's fast-paced society, six or seven hours of sleep may sound pretty good, Most healthy adults (students) need between seven and a half to eight hours of sleep per night to function at their best. The healthy duration for healthy 
sleep is not less than 6 hours and not more than 8 hours, to perform the work in a good way and be focused at the work time ${ }^{(8)}$.

The consequences of sleep problems-whether due to insufficient sleep or an untreated sleep disorder - can be serious. Sleep problems have been associated with deficits in attention and academic performance, drowsy driving, risk-taking behaviour and depression, impaired social relationships, and poorer health ${ }^{(9)}$. Wolfson and Carskadon reported that reduced sleep time, later bedtime and awakening, irregular sleep/wake patterns, and poor sleep quality negatively impacted adolescents' school performance ${ }^{(4)}$. The National Sleep Foundation found that high school students who reported insufficient sleep or daytime sleepiness also reported depressed mood and lower grades, whereas $80 \%$ of students who reported getting enough sleep made As and Bs in school. Among college students who carried a full academic load, those who reported poorer sleep quality were likely to perform worse on academic tests ${ }^{(3)}$.

Upon reading about this subject we found that many studies were done on this issue internationally, like a cross-sectional study that was done on the medical students of UFRN, in France on March of 2014. The study objective was to determine the effect of de-synchronization of the sleep-wake patterns on the quality of the academic performance. In conclusion, the study showed that students with irregular sleep patterns presented with sleepiness during daytime and demonstrated poorer academic performance and they were under higher academic load ${ }^{(10)}$. Another cross-sectional study was done in July 2014. The study was conducted on pharmacy students at Auburn University, USA. The study was done to assess the effect of sleep on the academic performance of pharmacy students. The study concluded that the average number of sleep hours needed for a healthy lifestyle is 7 hours per day, and that cognitive performance is susceptible to inadequate sleep durations ${ }^{(11)}$. A cross-sectional study was done at Combined Military Hospital Lahore Medical College (CMH LMC) and Institute of Dentistry, Lahore
(Pakistan).There two aims from this study were to determine the prevalence of psychological stress and pattern of sleeping difficulties among medical students. And to explore the relationship between academic stressors, psychological stress and poor sleeping habits among medical students. It took place from August 2014 to September 2014. The Conclusion of the study revealed a high prevalence of academic stress and poor sleep quality among medical students in Lahore. Academic stressors contributed significantly to perceived stress and sleep disorders.

A cross-sectional study was done on the nursing college students of KSU, in Saudi Arabia at Riyadh city (female section). The study objectives were to discuss the relationship between the sleep deprivation and academic performance of students in the college of nursing at KSU. In conclusion, the study showed that most of the subjects' academic performance was affected by sleep deprivation and other environmental factors ${ }^{(12)}$. Another crosssectional observational study was done in KSU it was conducted between December 2009 and January 2010 at the College of Medicine, King Saud University, Riyadh. This study aimed to assess the relationship between sleep habits and sleep duration with academic performance in medical students. The result showed Decreased nocturnal sleep time, late bedtimes during weekdays and weekends and increased daytime sleepiness are negatively associated with academic performance in medical students ${ }^{(13)}$.

Regionally, a cross-sectional, questionnaire-based, observational study carried out in spring 2009 among undergraduate students enrolled at AnNajah National University, Nablus. The aim of this study was to describe sleep habits and sleep problems in a population of undergraduates in Palestine. 400 students with a mean age of $20.2 \pm 1.3$ were studied. Sleep quality was reported as "poor" in only $9.8 \%$ and was significantly associated with sleep latency, the frequency of nocturnal awakenings, time of going to bed, nightmares but not with academic achievement ${ }^{(14)}$. 


\section{Problem Statement and Research Rationale:}

The college experience is of great value in providing emerging adults with a structured environment in which they can gain the knowledge, skills, and independence to contribute to society; however, this experience becomes so tiring and consuming for the students' energy. Nowadays students seem to be more sleep deprived than ever, which is caused by increasing pressure and workload on the students. Sleep effect on academic performance is inevitable as researches showed the effect of sleep hours and quality on memory, cognition and mood, although the prevalence of sleep disorders in college students has not been established. It is not known whether reported sleepiness among college students is simply due to insufficient sleep or whether it might be secondary to an undiagnosed sleep disorder. In addition, sleep patterns or disorders among college students may vary by gender or race/cultural affiliation. Growing evidence suggests poor sleep patterns are related to impaired academic performance, physical health and psychological wellbeing. That's the reason we need to find and prove the relationship between sleep and the academic performance of students.

\section{Objectives:}

This study aimed to:

1. To describe the sleep duration and timing among girl students in Al-Maarefa Colleges 2015-2016.

2. To identify the relationship between sleep duration and timing and academic performance of girl students in Al-Maarefa Colleges 20152016.

3. To identify the factors affecting the sleep patterns and sleep quality of students in AlMaarefa Colleges 2015-2016.

\section{Material and methods:}

\section{$>$ Study Design:}

It is an observational cross-sectional study.

\section{$>$ Study Area:}

This study was conducted in AlMaarefa colleges of Science and Technology which is located in AlRiyadh, KSA. It consists of 4 colleges; Medicine, Pharmacy, Applied science and Computer science. It has female and male sections. To graduate from colleges of pharmacy, applied science, and computer science the students need to finish 5 years divided into 10 levels, while the medical college it is 6 years divided into 12 levels.

\section{$>$ Study Population:}

The participants included in the study were female students studying in AlMaarefa colleges of Medicine, Pharmacy, Applied science, and Computer science. All students at levels higher than level 8 were excluded.

\section{$>$ Sampling:}

A quota sample of 150 students was surveyed.

\section{$>$ Data Needs:}

A. Variables

Information on college, level, demography, GPA and sleep pattern was collected.

B. Tools

A self-administered questionnaire was be used.

\section{$>$ Data Analysis:}

Data were analyzed using SPSS.

$>$ Ethical Consideration:

The research committee approval was taken to conduct this study. Individuals remained anonymous and they had the right to decide whether or not they get involved in this research. To ensure that confidentiality is truly protected the questionnaires were not numbered.

\section{Results}

Table (1): Only about $7 \%$ of the students slept at 8:00-9:55 p.m. on weekdays, and $48 \%$ of the students slept at 12:00-01:55 a.m. on the weekends. While $57 \%$ of the students slept after 2 a.m. on exam days.

Table (2): $52 \%$ of the students wake up at 06:00-07:55 a.m. on weekdays and 57\% of the students wake up after 10 a.m. on weekends, while $30 \%$ of the students wake up 04:00-05:55 a.m. of exam days.

Table (3): $33 \%$ of the students hap deep sleep on weekdays, $58 \%$ of the students had deep sleep on weekends, while only about $13 \%$ of the students had deep sleep on exam days. About $27 \%$ of the students suffered from nightmares. 
Table (4): Almost 53\% of the students had less than 6 hours of sleep on exam days.

Table (5): Almost $71 \%$ of the students felt tired when waking up multiple times a week, and felt sleepy during the day. While almost $87 \%$ of the students felt sleepy in lectures multiple times a week.

Table (6): $48 \%$ of the students had 3.1-4 GPA during the last semester.

Table (7): There was no relation between preparatory year GPA and number of sleep hours on prep year, ( $p$-value is 0.213 )
Table (8): there was a relation between sleep hours on weekdays and the last GPA ( $p$-value is $0.04)$

Table (9): There was a strong relationship between sleep hours on exam days and last GPA ( $\mathrm{p}$-value is 0.005 )

Table (10): There was no relation between, sleep quality on exam days and last GPA (pvalue 0.378$)$

Table (11) (12) (13): There were no relation between the major, level or sleep quality and duration of sleep (p-value $0.514,0.082,0.112$ ).

\begin{tabular}{lll}
\hline \multicolumn{2}{c}{ Table(1) Bedtime on weekdays, weekends, and exam days (N=150) } \\
\hline Weekdays & Frequency & Percent \\
before 8 pm & 4 & 2.7 \\
8:00-09:55 & 10 & $\underline{\mathbf{6 . 7}}$ \\
10:00-11:55 & 63 & 42.0 \\
\hline Weekends & Frequency & Percent \\
before 8 pm & 2 & 1.3 \\
08:00-09:55 & 1 & .7 \\
10:00-11:55 & 13 & 8.7 \\
12:00-01:55 & 72 & $\underline{\mathbf{4 8 . 0}}$ \\
after 2 am & 62 & 41.3 \\
\hline Exam days & Frequency & Percent \\
before 8 pm & 1 & .7 \\
8:00-09:55 & 6 & 4.0 \\
10:00-11:55 & 27 & 18.0 \\
12:00-01:55 & 30 & 20.0 \\
after 2 am & 86 & $\underline{\mathbf{5 7 . 3}}$ \\
Total & 150 & 100.0 \\
\hline
\end{tabular}

Only about 7\% of the students slept at 8:00-9:55 p.m. on weekdays, and 48\% of the students slept at 12:00-01:55 a.m. on the weekends. While 57\% of the students slept after 2 a.m. on exam days.

$52 \%$ of the students wake up at 06:00-07:55 a.m. on weekdays and 57\% of the students wake up after 10 a.m. on weekends, while 30\% of the students wake up 04:00-05:55 a.m. of exam days. 
Table (2) waking up on weekdays, weekends, and exam days (N=150) ; 2015-2016

\begin{tabular}{lll}
\hline Weekdays & Frequency & Percent \\
before 4 am & 4 & 2.7 \\
04:00-05:55 & 51 & 34.0 \\
06:00-07:55 & 78 & $\underline{\mathbf{5 2 . 0}}$ \\
08:00-09:55 & 10 & 6.7 \\
after 10 am & 7 & 4.7 \\
\hline \hline Weekends & Frequency & Percent \\
before 4 am & 2 & 1.3 \\
04:00-05:55 & 4 & 2.7 \\
06:00-07:55 & 17 & 11.3 \\
08:00-09:55 & 41 & 27.3 \\
after 10 am & 86 & $\mathbf{5 7 . 3}$ \\
\hline \hline Exam days & Frequency & Percent \\
before 4 am & 35 & 23.3 \\
04:00-05:55 & 45 & $\underline{\mathbf{3 0 . 0}}$ \\
06:00-07:55 & 32 & 21.3 \\
08:00-09:55 & 20 & 13.3 \\
after 10 am & 18 & 12.0 \\
Total & 150 & 100.0 \\
\hline
\end{tabular}

\begin{tabular}{lll}
\hline \multicolumn{1}{l}{ Table (3) Sleep quality on weekdays, } & weekends, and exam days $(\mathbf{N}=\mathbf{1 5 0})$ \\
\hline Weekdays & Frequency & Percent \\
Light & 61 & 40.7 \\
Deep & 50 & $\underline{\mathbf{3 3 . 3}}$ \\
Interrupted & 39 & 26.0 \\
\hline Exam days & Frequency & Percent \\
Light & 67 & 44.7 \\
Deep & 19 & $\underline{\mathbf{1 2 . 7}}$ \\
Interrupted & 64 & 42.7 \\
\hline Weekends & Frequency & Percent \\
Light & 33 & $\underline{\mathbf{2 2 . 0}}$ \\
Deep & 87 & $\underline{\mathbf{5 8 . 0}}$ \\
Interrupted & 30 & 20.0 \\
\hline \hline Nightmares & Frequency & Percent \\
Yes & 40 & $\underline{\mathbf{2 6 . 7}}$ \\
No & 110 & $\underline{\mathbf{7 3 . 3}}$ \\
Total & 150 & 100.0 \\
\hline
\end{tabular}

$33 \%$ of the students hap deep sleep on weekdays, $58 \%$ of the students had deep sleep on weekends, while only about $13 \%$ of the students had deep sleep on exam days. About $27 \%$ of the students suffered from nightmares.

Almost 53\% of the students had less than 6 hours of sleep on exam days. 


\begin{tabular}{lll}
\hline \multicolumn{2}{l}{ Table (4) Sleep hours on exam days $(\mathbf{N}=\mathbf{1 5 0})$} & \\
\hline & Frequency & Percent \\
less than normal & 79 & $\underline{\mathbf{5 2 . 7}}$ \\
Normal & 55 & 36.7 \\
more than normal & 16 & 10.7 \\
Total & 150 & 100.0 \\
\hline
\end{tabular}

Table (5) Activity level during the week ( $\mathrm{N}=150)$

Feeling tired when waking up

\begin{tabular}{lll} 
& Frequency & Percent \\
No & 44 & 29.3 \\
$1-2$ a week & 62 & $\underline{\mathbf{4 1 . 3}}$ \\
$3-5$ a week & 24 & $\underline{\mathbf{1 6 . 0}}$ \\
Everyday & 20 & $\underline{\mathbf{1 3 . 3}}$ \\
\hline \hline
\end{tabular}

Feeling sleepy during the day

\begin{tabular}{lll} 
& Frequency & Percent \\
No & 44 & 29.3 \\
1-2 a week & 62 & $\underline{\mathbf{4 1 . 3}}$ \\
3-5 a week & 24 & $\underline{\mathbf{1 6 . 0}}$ \\
Everyday & 20 & $\underline{\mathbf{1 3 . 3}}$ \\
\hline
\end{tabular}

Feeling sleepy in lectures

\begin{tabular}{lll} 
& Frequency & Percent \\
No & 19 & 12.7 \\
1-2 a week & 67 & $\underline{\mathbf{4 4 . 7}}$ \\
3-5 a week & 39 & $\underline{\mathbf{2 6 . 0}}$ \\
everyday & 25 & $\underline{\mathbf{1 6 . 7}}$ \\
Total & 150 & 100.0 \\
\hline
\end{tabular}

Almost $71 \%$ of the students felt tired when waking up multiple times a week, and felt sleepy during the day. While almost $87 \%$ of the students felt sleepy in lectures multiple times a week

$48 \%$ of the students had 3.1-4 GPA during the last semester.

\begin{tabular}{lll}
\hline \multicolumn{2}{l}{ Table (6) GPA at the study time $(\mathbf{N}=\mathbf{1 5 0})$} & \\
& Frequency & Percent \\
less than 2 & 19 & 12.7 \\
$2.1-3$ & 59 & 39.3 \\
$3.1-4$ & 72 & $\underline{\mathbf{4 8 . 0}}$ \\
Total & 150 & $\mathbf{1 0 0 . 0}$ \\
\hline
\end{tabular}


Table (7) Preparatory year sleep hours in relation to preparatory year GPA $(\mathrm{N}=150)$

\begin{tabular}{llllll} 
& & Prep year GPA & \multicolumn{3}{c}{ Total } \\
& & less than 2 & $2.1-3$ & 3.1 & \\
& & & & -4 & \\
Prep year sleep hours & less than 6 & 4 & 17 & 31 & 52 \\
& $6-8$ & 3 & 8 & 42 & 53 \\
& more than 8 & 2 & 14 & 29 & 45 \\
Total & 9 & 39 & 102 & 150 \\
\hline
\end{tabular}

There was no relation between preparatory year GPA and number of sleep hours on prep year, (pvalue is 0.213 )

There was a relation between sleep hours on weekdays and the last GPA (p-value is 0.04)

\begin{tabular}{|c|c|c|c|c|c|}
\hline \multicolumn{6}{|c|}{ Table (9) Sleep hours exams in relation to GPA at study time $(\mathrm{N}=150)$} \\
\hline \multirow{4}{*}{ Sleep hours exams } & \multirow{4}{*}{$\begin{array}{l}\text { less than normal } \\
\text { Normal } \\
\text { more than normal }\end{array}$} & \multicolumn{3}{|l|}{ GPA } & \multirow{2}{*}{$\begin{array}{l}\text { Total } \\
79\end{array}$} \\
\hline & & 8 & 33 & 38 & \\
\hline & & 5 & 21 & 29 & 55 \\
\hline & & 6 & 5 & 5 & 16 \\
\hline Total & & 19 & 59 & 72 & 150 \\
\hline
\end{tabular}

There was a strong relationship between sleep hours on exam days and last GPA (p-value is 0.005)

There was no relation between, sleep quality on exam days and last GPA (p-value 0.378

\begin{tabular}{|c|c|c|c|c|c|c|}
\hline \multicolumn{7}{|c|}{ Table (10) Sleep hours on exam days in relation to Major $(\mathrm{N}=150)$} \\
\hline & & \multicolumn{4}{|l|}{ Major } & \multirow[t]{2}{*}{ Total } \\
\hline & & Medicine & $\begin{array}{l}\text { pharma } \\
\text { D }\end{array}$ & $\begin{array}{l}\text { respiratory } \\
\text { therapy }\end{array}$ & nursing & \\
\hline Sleep hrs & less than normal & 34 & 29 & 12 & 4 & 79 \\
\hline on exam & Normal & 35 & 13 & 7 & 0 & 55 \\
\hline days & more than normal & 7 & 4 & 5 & 0 & 16 \\
\hline Total & & 76 & 46 & 24 & 4 & 150 \\
\hline
\end{tabular}


Table (11) Sleep quality exams in relation to GPA at study time $(\mathrm{N}=150)$

\begin{tabular}{|c|c|c|c|c|c|}
\hline \multicolumn{6}{|c|}{ Table (12) sleep hours exam days in relation to level $(\mathrm{N}=150)$} \\
\hline \multirow{5}{*}{$\begin{array}{l}\text { Sleep hrs on exam } \\
\text { days }\end{array}$} & & level & & & \multirow[t]{2}{*}{ Total } \\
\hline & & $3-4$ & $5-6$ & $7-8$ & \\
\hline & less than normal & 16 & 35 & 28 & 79 \\
\hline & Normal & 12 & 17 & 26 & 55 \\
\hline & more than normal & 2 & 7 & 7 & 16 \\
\hline Total & & 30 & 59 & 61 & 150 \\
\hline
\end{tabular}

There were no relation between the major, level or sleep quality and duration of sleep (p-value 0.514 , $0.082,0.112$ ).

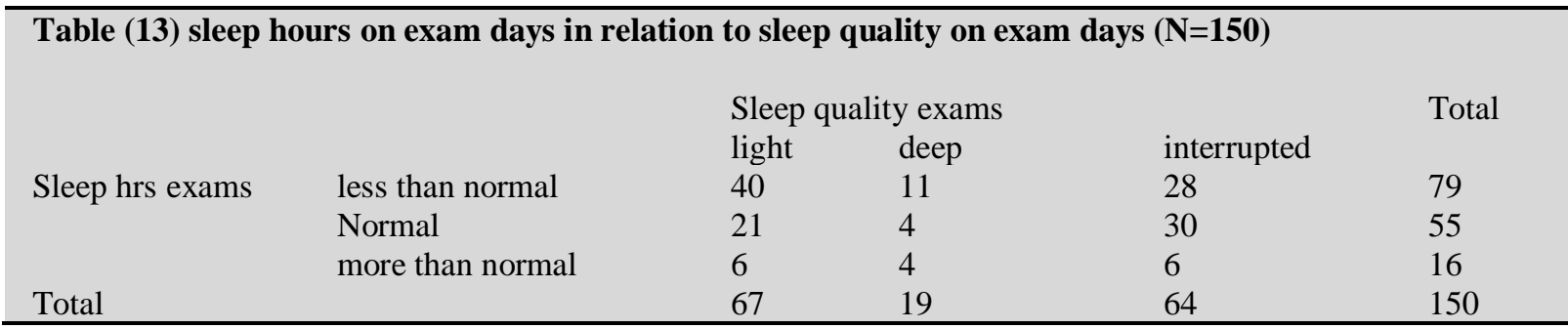

\section{Discussion}

In this study, it was found that high frequency of students slept at late times. In contrast, a study done in Palestine showed that $58.3 \%$ of students went to bed before midnight ${ }^{(12)}$. This difference may be due to the differences in social life patterns between the two countries. This study showed a high frequency of waking up early in the morning. In contrast to the study done in Palestine that showed that only $18 \%$ of the total sample woke up before 6 am ${ }^{(12)}$.This dissimilarity may be due to the difference in majors of participants.

In this study, high prevalence in participants were suffering from poor sleep quality, similarly, a study done in Saudi Arabia found that $49.15 \%$ of students suffered from bad sleep quality ${ }^{(12)}$.This may be due to common social patterns and similarity in educational level. The present work identified that about half of the students had less than 6 hours of sleep on exam days. Similarly, a study done in Saudi Arabia found that $95.6 \%$ of the students get less than 6 hours /day of sleep on the final exams ${ }^{(12)}$. This similarity may be because the sample taken for both studies were from similar age and educational level groups and same environment.

In this study, a relation between sleep duration and activity level during the day was found. Another study done in the USA found more than half of the respondents $(54.4 \%)$ reported feeling tired when waking up almost every day ${ }^{(11)}$. This similarity may be because the participants were from similar majors, and it's well known that little sleep hours result in tiredness in the following day.

In this study, a relation between sleep hours on weekdays and GPA was found. A similarity was found with a study done in France that showed a correlation between sleep length and academic performance $(\mathrm{p}<0.02)^{(10)}$.This similarity may be because of the similarity in the educational level of the participants. In this study a strong relationship between sleep hours on exam days and last GPA was found, similarly a study done in France showed a correlation between irregularity of sleep and academic performance ( $\mathrm{p}<$ 0.03 ), implying that the students with a more irregular sleep-wake cycle and a shorter length of the sleep presented worse academic performance ${ }^{(10)}$. Another_study done in the USA found significant associations between final course grade and sleep duration on the night prior to an examination $\quad(p=0.006) \quad$ (11) $\quad$ Those similarities may be because participants in those studies were formed similar age groups and educational levels.

\section{Conclusion}


The data collected showed a high prevalence of insufficient sleep hours generally, and on exam nights specifically and a strong relationship between exam day sleeping hours and the final GPA. The average GPA remained high, even when the number of sleeping hours declined compared to preparatory year sleeping hours.

\section{Recommendations}

- Students should get at least 6 hours of sleep per night, especially on exam days.

- Factors that affect their sleep quality should be avoided.

- Sleep hours should be in night time better than daytime naps.

- Sleep schedules should be maintained regularly.

\section{Acknowledgement:}

We would like to express our special thanks, gratitude and appreciation to our supervisor Dr. Mona Hassan who taught us how to do a research properly and professionally. And so this project is attributing to her help.

Secondly we would also like to thank the families and friends who encouraged each one of us to exert their utmost efforts in order to finalize this project within the limited time frame.

\section{References}

1. Yang C, Wu C, Hsieh $\mathrm{M}$ et al.(2003): Coping with sleep disturbances among young adults: a survey of first-year college students in Taiwan. Behavioral medicine, 29(3): 133-138.

2. Gaultney J (2010): The prevalence of sleep disorders in college students: impact on academic performance. Journal of American College Health,59(2): 91-97.

3. Wolfson A, Carskadon M (2003): Understanding adolescent's sleep patterns and school performance: a critical appraisal. Sleep medicine reviews, 7(6): 491-506.

4. Walker MP, and Stickgold R(2009): Sleep and Memory Consolidation. In: Chokroverty S, editor. Sleep disorders medicine: Basic science, technical considerations, and clinical aspects. 3rd edn. Saunders, an imprint of Elsevier Inc: Philadelphia.

5. Curcio G, Ferrara M, De Gennaro L (2006): Sleep loss, learning capacity and academic performance. Sleep medicine reviews, 10(5): 323-337.

6. Hirshkowitz M, Whiton K, Albert S $M$ et al .(2015): National Sleep Foundation's sleep time duration recommendations: methodology and results summary. Sleep Health, 1(1): 40-43.

7. Smaldone A, Honig J C, Byrne M W (2007): Sleepless in America: inadequate sleep and relationships to health and well-being of our nation's children. Pediatrics ,119(1): S29-S37.

8. Medeiros A L, Mendes D B, Lima $P$ Fet al. (2001): The relationships between sleep-wake cycle and academic performance in medical students. Biological Rhythm Research, 32(2): 263-270

9. Zeek M L, Savoie M J, Song M et al .(2015): Sleep duration and academic performance among student pharmacists. American journal of pharmaceutical education, 79(5): 63.

10. Waqas A, Khan S, Sharif W et al. (2015):Association of academic stress with sleeping difficulties in medical students of a Pakistani medical school: a cross sectional survey. PeerJ., 3: e840.

11. Al Ghamdi A A (2013): Sleep deprivation and academic performance of students in the collage of nursing at king saud university. World Applied Sciences Journal, 27(2):155-67.

12. BaHammam A $S$, Alaseem A $M$, Alzakri A A et al. (2012): The relationship between sleep and wake habits and academic performance in medical students: a cross-sectional study. BMC medical education, 12(1): 61. 
Abrar Al-mutairi et al. 